\title{
CONTRAPONTO MÉTRICO E SEMANTIZAÇÃO DA FORMA NUM POEMA DE FERNANDO PESSOA
}

\author{
Paulo Henriques Britto* \\ Pontifícia Universidade Católica do Rio de Janeiro
}

\begin{abstract}
Resumo: Recorrendo à noção de contraponto métrico desenvolvida em trabalho anterior, o autor demonstra a existência de uma densa estrutura métrica no poema "Pierrot bêbado" de Fernando Pessoa, que pode ser analisada como consistindo em dois níveis em relação de contraponto. Além disso, mostra-se também que o contraponto métrico interage com o plano do sentido do poema, na medida em que o personagem mencionado no título se manifesta no corpo do poema essencialmente através de uma inversão de termos na relação de contraponto.

Palavras-chave: Contraponto métrico. Versificação portuguesa. Fernando Pessoa.
\end{abstract}

\section{METRICAL COUNTERPOINT AND SEMANTICIZATION OF FORM IN A POEM BY FERNANDO PESSOA}

\begin{abstract}
Relying on the notion of metrical counterpoint developed in an earlier article, the author demonstrates the existence of a dense metrical structure in Fernando Pessoa's poem "Pierrot bêbado" which may be analyzed as consisting of two levels in a relationship of counterpoint. It is also shown that the metrical counterpoint interacts with the semantic level, in that the character of Pierrot mentioned in the title appears in the body of the poem mostly as an inversion in the counterpointed meters.

Keywords: Metrical counterpoint. Portuguese versification. Fernando Pessoa.
\end{abstract}

\footnotetext{
* Formação em Língua Inglesa e Portuguesa, Pontifícia Universidade Católica do Rio de Janeiro. Mestrado em Letras, Pontifícia Universidade Católica do Rio de Janeiro. Título de Notório Saber, Pontifícia Universidade Católica do Rio de Janeiro. Professor associado da Pontifícia Universidade Católica do Rio de Janeiro. Rio de Janeiro, Rio de Janeiro, Brasil. E-mail: phbritto@hotmail.com
} 


\section{Introdução}

Num trabalho anterior (BRITTO, 2009), apresentei uma proposta de análise métrica em português que utiliza um conceito de "contraponto métrico" já utilizado pelos estudiosos da prosódia inglesa, principalmente quando se trata de poemas escritos em formas metricamente regulares. Trata-se da relação de aproximação e afastamento, sincronia e contraste, que se estabelece entre um padrão rítmico ideal (dito metro, contrato métrico ou receita métrica do poema), presente na consciência e mesmo no corpo do leitor, e o ritmo real, necessariamente irregular, manifestado no poema como fenômeno fônico. Porém o poeta inglês Gerard Manley Hopkins, na segunda metade do século XIX, já apontava para a possibilidade de haver dois padrões contrastantes ainda no nível do contrato métrico, antes mesmo de chegarmos ao nível do ritmo real, audível, do poema. Afirma Hopkins, no seu "Author's preface":

Chamo de pé invertido a colocação do acento no lugar em que, a julgar pelo resto do compasso, deveria estar a atonia, e a atonia no lugar do acento [...]. Se, porém, a inversão é repetida em dois pés seguidos [...] trata-se ou de uma grave deficiência de ouvido ou então de um efeito calculado, a superindução ou sobreposição [mounting] de um novo ritmo sobre o antigo; e como o ritmo novo ou sobreposto é ouvido e a mente naturalmente fornece o ritmo natural ou padrão anterior, pois não esquecemos qual é o ritmo que deveríamos estar ouvindo, dois ritmos de algum modo correm ao mesmo tempo, e temos algo equivalente ao contraponto na música, ou seja, duas ou mais linhas melódicas correndo ao mesmo tempo, e isso é o Contraponto Rítmico. (HOPKINS, 1976, p. 8-9)

Mais exatamente, teríamos dois esquemas rítmicos ainda no nível mais abstrato do chamado contrato métrico, formando um complexo pano de fundo para um terceiro ritmo, o ritmo real do 
plano sonoro em si, com todas as suas irregularidades. No trabalho anterior, antes de tentar demonstrar de que modo o uso do contraponto métrico já está codificado em alguns metros canônicos do português, sendo particularmente relevante para o estabelecimento da oposição entre o heroico e o sáfico, analiso um caso de contraste entre dois contratos métricos presentes num poema de Drummond que tem uma implicação semântica: em "José", a passagem "Se você gritasse, se você gemesse, se você tocasse, a valsa vienense" é marcada pela introdução de um ritmo de caráter ternário - e portanto associado ao semantema "valsa" - num dos dois níveis da métrica. Meu objetivo no presente trabalho é examinar um outro caso de contraponto rítmico com implicações semânticas, só que bem mais complexas do que no exemplo de Drummond; desta vez, observo o fenômeno num poema de Fernando Pessoa.

\section{Contraponto rítmico em "Pierrot bêbado"}

O poema "Pierrot bêbado" é o item de número três de uma série intitulada "Ficções do interlúdio". A versão manuscrita que se conhece do poema é datada de 17/10/1913, mas ele só foi publicado em novembro de 1917, juntamente com os outros quatro poemas da série (PESSOA, 2006, 488). Todos os poemas de "Ficções do interlúdio" são marcadamente musicais, com rimas insistentes e esquemas métricos cuidadosos. Eis a íntegra do poema (PESSOA, 2006, p. 456):

\section{PIERROT BÊBADO}

Nas ruas da feira,

Da feira deserta,

Só a lua cheia

Branqueia e clareia

As ruas da feira

$\mathrm{Na}$ noite entreaberta. 
Só a lua alva

Branqueia e clareia

A paisagem calva

De abandono e alva

Alegria alheia.

Bêbada branqueia

Como pela areia

Nas ruas da feira,

Da feira deserta,

Na noite já cheia

De sombra entreaberta.
A lua branqueia
Nas ruas da feira
Deserta e incerta...

No quadro abaixo, apresentamos uma escansão tradicional do poema. Na segunda coluna, usamos o símbolo / para indicar acento primário e - para indicar sílaba átona. Na terceira, os números indicam as sílabas acentuadas do verso correspondente. Na quarta, temos a representação do esquema de rimas.

\section{Tabela 1}

\begin{tabular}{|l|l|l|l|}
\hline PIERROT BÊBADO & & & \\
Nas ruas da feira, & $-/--/-$ & $2-5$ & $a$ \\
Da feira deserta, & $-/--/-$ & $2-5$ & $b$ \\
Só a lua cheia & $/-/-/-$ & $1-3-5$ & $a$ \\
Branqueia e clareia & $-/--/-$ & $2-5$ & $a$ \\
As ruas da feira & $-/--/-$ & $2-5$ & $a$ \\
Na noite entreaberta. & $-/--/-$ & $2-5$ & $b$ \\
& & & \\
\hline
\end{tabular}




\begin{tabular}{|l|l|l|l|}
\hline Só a lua alva & $/-/-/-$ & $1-3-5$ & $c$ \\
Branqueia e clareia & $-/--/-$ & $2-5$ & $a$ \\
A paisagem calva & $--/-/-$ & $3-5$ & $c$ \\
De abandono e alva & $--/-/-$ & $3-5$ & $c$ \\
Alegria alheia. & $--/-/-$ & $3-5$ & $a$ \\
& & & \\
Bêbada branqueia & $/---/-$ & $1-5$ & $a$ \\
Como pela areia & $/-/-/-$ & $1-3-5$ & $a$ \\
Nas ruas da feira, & $-/--/-$ & $2-5$ & $a$ \\
Da feira deserta, & $-/--/-$ & $2-5$ & $b$ \\
Na noite já cheia & $-/--/-$ & $2-5$ & $a$ \\
De sombra entreaberta. & $-/-$ - / - & $2-5$ & $b$ \\
& $-/-$ - / - & $2-5$ & $a$ \\
A lua branqueia & $-/-$ - / - & $2-5$ & $a$ \\
Nas ruas da feira & $-/--/-$ & $2-5$ & $b$ \\
Deserta e incerta... &
\end{tabular}

À primeira vista, temos a impressão de que o metro do poema é uniforme: todos os versos têm cinco sílabas. Mas se ouvimos o poema lido em voz alta, percebemos que há na verdade dois ritmos contrastantes, que se alternam em diferentes seções do poema. Examinando a terceira coluna da tabela, percebemos de onde vem à variação rítmica: por um lado, em alguns versos o acento recai na segunda sílaba; por outro lado, há versos em que o acento é deslocado para a terceira, para a terceira e a primeira ou (num único caso) apenas para a primeira. A diferença entre esses dois padrões de acentuação, como se verá adiante, é crucial. Observamos também que temos três rimas diferentes. Retomemos a tabela acima, desta vez utilizando sombreados diferentes para destacar, na terceira coluna, os versos que apresentam um ritmo contrastante com o resto do poema, e marcas gráficas para assinalar as três rimas. 


\section{Tabela 2}

\begin{tabular}{|l|l|l|l|}
\hline PIERROT BÊBADO & & & \\
Nas ruas da feira, & $-/--/-$ & $2-5$ & $a$ \\
Da feira deserta, & $-/--/-$ & $2-5$ & $b$ \\
Só a lua cheia & $/-/-/-$ & $1-3-5$ & $a$ \\
Branqueia e clareia & $-/--/-$ & $2-5$ & $a$ \\
As ruas da feira & $-/--/-$ & $2-5$ & $a$ \\
Na noite entreaberta. & $-/--/-$ & $2-5$ & $b$ \\
& & & \\
Só a lua alva & $/-/-/-$ & $1-3-5$ & $c$ \\
Branqueia e clareia & $-/--/-$ & $2-5$ & $a$ \\
A paisagem calva & $--/-/-$ & $3-5$ & $c$ \\
De abandono e alva & $--/-/-$ & $3-5$ & $\mathrm{c}$ \\
Alegria alheia. & $--/-/-$ & $3-5$ & $\mathrm{a}$ \\
& & & \\
Bêbada branqueia & $/---/-$ & $1-5$ & $\mathrm{a}$ \\
Como pela areia & $/-/-/-$ & $1-3-5$ & $\mathrm{a}$ \\
Nas ruas da feira, & $-/--/-$ & $2-5$ & $\mathrm{a}$ \\
Da feira deserta, & $-/--/-$ & $2-5$ & $\mathrm{~b}$ \\
Na noite já cheia & $-/--/-$ & $2-5$ & $\mathrm{a}$ \\
De sombra entreaberta. & $-/--/-$ & $2-5$ & $\mathrm{~b}$ \\
& & & \\
A lua branquei & $-/--/-$ & $2-5$ & $\mathrm{a}$ \\
Nas ruas da feira & $-/--/-$ & $2-5$ & $\mathrm{a}$ \\
Deserta e incerta... & $-/--/-$ & $2-5$ & $\mathrm{~b}$ \\
\hline
\end{tabular}

A terceira coluna mostra que o poema pode ser dividido, sob o aspecto métrico, em três seções. (Vamos nos referir às estrofes como $\mathrm{A}, \mathrm{B}, \mathrm{C}$ e $\mathrm{D}$, e aos versos pelo número equivalente a sua posição dentro da estrofe.) De modo aproximado, podemos dizer que a estrofe A é marcada pelo metro que denominaremos de metro 
principal, o trecho $\mathrm{B} 1$ a $\mathrm{C} 2$ pelo metro que chamaremos de contrastante, e C3 até o final novamente pelo metro principal. Em A3 temos uma antecipação do metro contrastante ainda na seção em metro principal, e a passagem B1-2 é uma transição que pode ser encarada ou como contendo uma antecipação do metro contrastante em território do metro principal ou como um eco final do principal em território do contrastante. Já a fronteira entre a segunda e a terceira seções métricas é bem nítida: a partir de C3, o metro contrastante desaparece para sempre do poema.

Inicialmente, podemos caracterizar o metro principal como formado por um jambo seguido de um dáctilo seguido por um jambo, e o contrastante como uma sequência de três troqueus, pois mesmo nos versos em que apenas a terceira e a quinta sílabas recebem acento, como no trecho B3-5, é possível inserir um acento secundário na primeira sílaba. Mas essa análise não leva em conta o fato de que os versos são lidos em sucessão, e não isoladamente. Se escandirmos sucessivamente três versos da primeira seção em metro principal, A4-6, teremos um resultado bem diferente da análise de um verso individual:

\section{Branqueia e clareia / As ruas da feira / Na noite entreaberta}

Três versos sucessivos geram uma cadeia de dáctilos, iniciada por uma anacruse. A sílaba átona final de cada verso (todos os versos do poema são graves) soma-se à primeira sílaba átona inicial do verso seguinte, de modo que se na análise anterior tínhamos em cada verso um dáctilo precedido e seguido por um jambo, no contexto maior do poema fica claro que o metro primário é rigorosamente dactílico. Quanto ao metro contrastante, analisemos a passagem B5-C2:

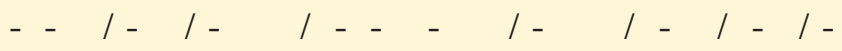

Alegria alheia. / Bêbada branqueia / Como pela areia 
Aqui o padrão métrico pode parecer menos claro do que no caso do metro principal, mas se acrescentarmos os acentos secundários do trecho, o metro trocaico se evidencia:

\section{$1-1-1-1-1-1-1-1-1-$}

Alegria alheia. / Bêbada branqueia / Como pela areia

Resumindo o que vimos até agora: todos os versos de "Pierrot bêbado" são pentassilábicos e graves, e podem ser divididos em dois metros diferentes: o metro principal, de caráter dactílico (e portanto ternário), predomina no início e no final do poema, enquanto a seção intermediária é marcada pelo que denominamos metro contrastante, que é trocaico (e portanto binário).

A divisão do poema em três seções rítmicas é reforçada pelo esquema de rimas. Como indica a quarta coluna, há uma seção inicial (estrofe A) em que só aparecem as rimas $a$ e $b$; em seguida temos uma segunda seção iniciada em B1 em que predomina a rima $c$, com ocorrência também de $a$. O final da seção, porém, é difícil de definir, pois entre B5 e C3 só aparece a rima $a$, que é comum à primeira e à segunda seções. Em $\mathrm{C} 4$ reaparece a rima $b$, que se alterna com $a$ até o final, tal como na primeira seção. Assim, tanto no plano da métrica quanto no da rima o poema se divide em três seções, embora a coincidência entre as divisões métricas e as rímicas não seja exata.

Porém a questão do metro é ainda mais complexa do que já foi visto até agora. Dissemos que o metro principal é de caráter ternário (dactílico) e que o contrastante é binário (trocaico). Essa observação se aplica apenas ao primeiro nível de análise. Há um outro padrão rítmico que se sobrepõe a esse primeiro nível: aquele que é determinado pelo posicionamento dos acentos que coincidem com as sílabas finais dos versos, onde ocorrem as rimas, em relação aos acentos que ocorrem no meio dos versos. Porque é evidente que a posição final no verso, ressaltada pela presença da rima, determina que esses acentos sejam mais fortes do que os outros. Voltemos a examinar a passagem A4-6, que tomamos como exemplo do ritmo 
principal, porém desta vez assinalemos com o símbolo // os acentos primários que coincidem com a posição final no verso, que por esse motivo são mais fortes que os outros:

Branqueia e clareia / As ruas da feira / Na noite entreaberta

Esta marcação deixa claro um fato que até então estava obscurecido (mas que, numa leitura em voz alta do trecho, torna-se evidente): por cima do padrão ternário estabelecido pelos dáctilos dos três versos sentimos um segundo padrão métrico, formado pela sucessão de acentos finais e acentos mediais, em que aqueles representam o tempo forte e estes o tempo fraco; e este segundo padrão métrico, que estabelece um contraponto com o primeiro, é binário e não ternário. Utilizando uma notação musical tradicional, podemos representar o novo padrão assim:

\section{Diagrama 1}

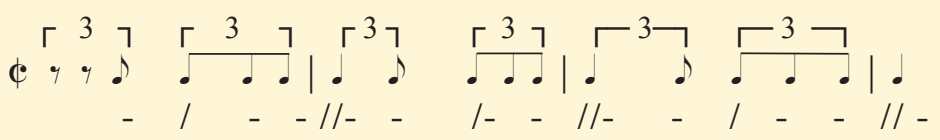

Branqueia e clareia / As ruas da feira / Na noite entreaberta

Examinemos a notação musical acima. Podemos considerar que o trecho em questão contém quatro compassos musicais. Esses compassos, em ritmo binário $-\dot{\phi}$, ou ${ }_{2}^{2}-$ têm início no tempo forte assinalado pelas sílabas finais dos versos, onde ficam as rimas.

Se aplicarmos uma análise semelhante ao trecho B5-C2, tomado como representativo do ritmo contrastante, temos o seguinte: 


\section{Diagrama 2}

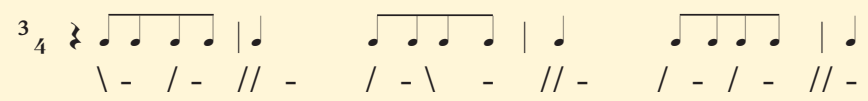

Alegria alheia. / Bêbada branqueia / Como pela areia

Se, num primeiro nível, havíamos estabelecido que o metro contrastante era trocaico, e portanto binário, quando consideramos os finais de verso como acentos que delimitam inícios de compassos musicais, temos que, neste segundo nível de análise, o metro da passagem é na verdade de caráter ternário, pois entre cada dois inícios de compasso temos mais dois acentos (primários ou secundários) a separá-los. Ou seja: na seção do poema em ritmo contrastante, temos uma situação que é precisamente o oposto da que observamos nas outras duas seções. Esquematizando:

\section{Tabela 3}

\begin{tabular}{|l|l|l|}
\hline & $1^{\circ}$ NÍVEL & $2^{\circ}$ NÍVEL \\
\hline $\begin{array}{l}\text { METRO PRINCIPAL } \\
\text { (seções 1 e 3) }\end{array}$ & dactílico (ternário) & $2_{2}$ (binário) \\
\hline $\begin{array}{l}\text { METRO CONTRASTANTE } \\
\text { (Seção 2) }\end{array}$ & trocaico (binário) & ${ }_{4}{ }_{4}$ (ternário) \\
\hline
\end{tabular}

Até aqui demonstramos que só é possível fazer justiça à complexidade da estrutura rítmica de "Pierrot bêbado" se a análise for realizada em mais de um nível. Trivialmente, temos que todos os versos do poema são pentassílabos graves; se os versos forem analisados lado a lado e não em isolamento, porém, verificamos que em 13 deles, que predominam no início e no final do poema, temos uma cadeia de dáctilos; nos 7 restantes, concentrados na seção intermediária, o metro é claramente trocaico. Mas se, além disso, realizarmos uma análise adicional, na qual se atribua peso maior 
à última sílaba acentuada de cada verso, verificamos que, nesse nível final, as seções em metro principal na verdade têm um metro binário que contrasta com o caráter ternário dos pés em que se subdividem os versos, enquanto que na seção intermediária o caráter binário do trecho determina - através do contraste entre os acentos mais fortes das sílabas finais e os acentos mais fracos em posição medial no verso - um metro ternário. Resta indagar, porém: essa complexa estrutura rítmica terá alguma funcionalidade no poema?

\section{Implicações semânticas do contraponto métrico}

Numa leitura do poema que atente para o aspecto semântico, um primeiro fato chama a atenção é o contraste entre o título e o corpo do poema. O título, "Pierrot bêbado", evoca um personagem, "Pierrot", e um atributo seu, "bêbado". No corpo do poema, porém, temos apenas a descrição de uma paisagem urbana: trata-se de uma cena noturna, ruas onde houve recentemente uma feira, iluminada pelo luar. A associação entre a figura do Pierrô ébrio e a lua é convencional no momento finissecular em que Pessoa se formou como poeta. Ela aparece no livro Pierrot lunaire do poeta simbolista belga Albert Giraud, publicado em 1884, musicado em 1912 por Schoenberg; em L'imitation de Notre-Dame de la Lune de Jules Laforgue (1886), e também outras obras. Que o complexo Pierrô bêbado-luar fazia parte do imaginário europeu da época é o que demonstra também o desenho de Adolphe Willette, publicado no periódico Le chat noir, editado pelo cabaré parisiense homônimo, em 17 de janeiro de 1885, que reproduzimos abaixo. 


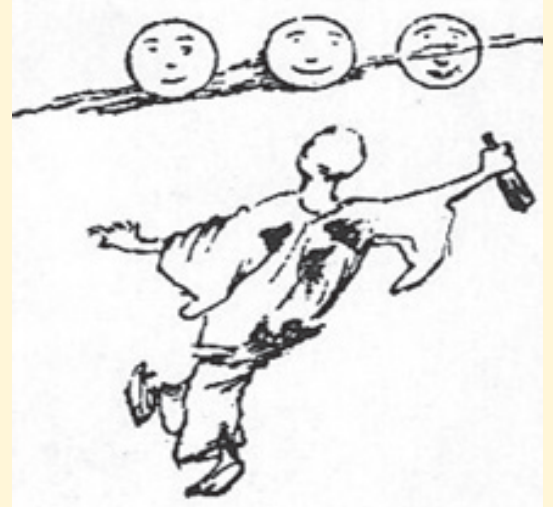

No poema, a única presença explícita nas ruas da feira deserta é a lua cheia, e o adjetivo "bêbada" aparece no feminino, claramente associado à lua. Mas a associação metonímica entre lua e Pierrô é clara.

Voltemos ao texto do poema, tal como ele aparece na nossa segunda tabela. O título nos apresenta a figura do Pierrô bêbado, mas os dois versos iniciais, A1-2, nos mostram as ruas desertas da feira, estabelecendo um ritmo binário composto de módulos rítmicos ternários (o que representamos musicalmente como um trecho em compasso ${ }_{2}^{2}$, com as notas agrupadas em quiálteras de três notas cada). Porém A3, cujo teor é "Só a lua cheia", introduz de modo inequívoco, com três acentos primários, o metro contrastante: um sucessão de três troqueus que quebra a cadeia de dáctilos e interrompe o ritmo binário do segundo nível. O verso seguinte, porém, restabelece o metro principal, de modo que $\mathrm{A} 3$ não chega ainda a estabelecer um metro contrastante, agindo apenas como uma quebra do ritmo já instaurado. Os três versos seguintes retornam ao metro principal, tal como o sentido dos versos reafirma o cenário de final de feira já desenhado, ruas vazias enluaradas; porém A6 fecha a estrofe e a sentença qualificando a noite como "entreaberta". Mas aberta para quê?

$\mathrm{O}$ verso inicial da segunda estrofe, $\mathrm{B} 1$, retoma o ritmo de A3 e a maior parte do conteúdo semântico do verso, sendo a única 
diferença a substituição do adjetivo "cheia" por "alva". Porém B2 repete o verso A4, e portanto restaura o metro principal; em seguida, a sequência B3-C2 afirma o metro já prenunciado em A3: uma sequência de pés binários (troqueus) que cria um ritmo ternário no nível superior. No trecho compreendido entre A6 e B3 temos, pois, três mudanças de metro num intervalo de apenas quatro versos. Essa instabilidade rítmica, como já vimos, é seguida por uma passagem de cinco versos em que se afirma o metro contrastante, e no penúltimo verso dessa passagem, $\mathrm{C} 1$, o adjetivo "bêbada", embora no feminino, evoca de modo inequívoco o Pierrô bêbado do título. Na passagem de $\mathrm{C} 2$ para $\mathrm{C} 3$, a volta do metro principal é nítida, ao contrário da irrupção do metro contrastante entre $\mathrm{A} 3 \mathrm{e}$ B3, marcada por idas e vindas: a partir de C3, que repete o verso $\mathrm{A} 1$ (seguido de $\mathrm{C} 4$, que repete $\mathrm{A} 2$ ), retornamos abruptamente para o metro principal da primeira seção do poema, ao mesmo tempo em que a mesma imagem de ruas noturnas desertas é reafirmada.

Se examinarmos novamente a nossa segunda tabela, veremos que a passagem em metro contrastante forma, em relação aos versos em metro principal que a antecedem e seguem, uma espécie de figura contra um fundo. $\mathrm{O}$ fundo - marcado pelo ritmo binário formado a partir de células rítmicas ternárias - é um cenário noturno urbano de final de feira, centrado no item lexical "ruas"; a figura - que corresponde ao ritmo ternário estabelecido por células rítmicas binárias, e também à entrada em cena da rima $c$, que só aparece nesta seção - está associada a "lua": observe-se que tanto na primeira irrupção do metro contrastante (A3) quanto na segunda (B1) o ritmo novo é deflagrado pela sequência "Só a lua...". Mas a lua, como já vimos, está metonimicamente ligada à figura de Pierrô, no contexto cultural em que o poema foi produzido. Assim, a instabilidade métrica da passagem A6-B3, após um trecho inicial ritmicamente bem estável, evoca a ideia do passo trôpego do bêbado - o Pierrô do título - cuja aproximação já fora prenunciada em A3; sua verdadeira entrada em cena, marcada pela instabilidade métrica que corresponde a seu andar de bêbado, se dá em A6-B3. Entre C2 e C3, porém, a figura de Pierrô - que atravessou a seção 
central do poema representada no plano lexical pela lua e no plano prosódico pela instabilidade rítmica seguida do estabelecimento de um metro contrastante - desaparece do poema, que termina com a volta do metro principal e uma reiteração um pouco modificada dos versos iniciais. Podemos, pois, esquematizar o poema assim:

\section{Tabela 4}

\begin{tabular}{|c|c|c|c|c|}
\hline \multicolumn{5}{|l|}{ PIERROT BÊBADO } \\
\hline Nas ruas da feira, & -/--/- & $2-5$ & $a$ & \\
\hline Da feira deserta, & $-/--/-$ & $2-5$ & $b$ & $1^{\circ}$ movimento (A1-6): \\
\hline Só a lua cheia & $|-|-\mid-$ & $1-3-5$ & $a$ & Predomínio do fundo \\
\hline Branqueia e clareia & -/--/- & $2-5$ & $a$ & ("ruas"), com prenúncio \\
\hline As ruas da feira & -/--/- & $2-5$ & $a$ & da figura ("lua") em A3 \\
\hline Na noite entreaberta. & $-/--/-$ & $2-5$ & $b$ & \\
\hline Só a lua alva & $|-/-|-$ & $1-3-5$ & $c$ & $2^{\circ}$ movimento (B1-C2): \\
\hline Branqueia e clareia & $-/--/-$ & $2-5$ & $a$ & Predomínio da figu- \\
\hline A paisagem calva & $--/-/-$ & $3-5$ & $c$ & ra ("lua", associada a \\
\hline De abandono e alva & $--/-/-$ & $3-5$ & $c$ & "Pierrot") com breve \\
\hline Alegria alheia. & $--/-/-$ & $3-5$ & $a$ & $\begin{array}{l}\text { irrupção do fundo em } \\
\text { B2; ocorrência da rima } c \text {; }\end{array}$ \\
\hline Bêbada branqueia & |---/- & $1-5$ & $a$ & "bêbada" em C1 \\
\hline Como pela areia & $\mid-/-/-$ & $1-3-5$ & $a$ & \\
\hline Nas ruas da feira, & -/--/- & $2-5$ & $2-5$ & \\
\hline Da feira deserta, & $-/--/-$ & $2-5$ & $2-5$ & \\
\hline Na noite já cheia & -/--/- & $2-5$ & $2-5$ & $3^{\circ}$ movimento $(C 3-D 3)$ : \\
\hline De sombra entreaberta. & $-/--/-$ & $2-5$ & $2-5$ & $\begin{array}{l}\text { Reafirmação do fundo } \\
\text { ("ruas"), desaparecimen- }\end{array}$ \\
\hline A lua branqueia & $-/--/-$ & $2-5$ & $2-5$ & to da figura e da rima $c$ \\
\hline Nas ruas da feira & -/--/- & $2-5$ & $2-5$ & \\
\hline Deserta e incerta... & $-/--/-$ & $2-5$ & $2-5$ & \\
\hline
\end{tabular}


Em "Pierrot bêbado", pois, Pessoa estabelece uma densa rede de correspondências entre os níveis do metro, da rima e do sentido, de tal modo que a figura do Pierrô mencionada no título se realiza no poema indiretamente, através da imagem da lua a ela associada e do estabelecimento de um novo padrão métrico que contrasta com o metro principal do poema. A relação contrapontística entre o metro no primeiro nível (o da célula métrica) e o metro no segundo nível (o estabelecido pelas relações entre acento final e acentos mediais no verso) se dá, no metro contrastante, de modo exatamente contrário ao que vemos no metro principal. E como há uma clara relação entre metro e sentido, na medida em que figura e fundo correspondem a padrões métricos específicos - uma relação acentuada ainda mais pelo esquema de rimas - não seria exagero falar, no contexto desse poema, em semantização da forma: o uso de elementos formais - metro e rima - de modo a reforçar o significado expresso pelos itens lexicais.

\section{Referências}

BRITTO, Paulo H. O conceito de contraponto métrico em versificação. Poesia Sempre, Rio de Janeiro, n. 31, p. 71-83, 2009.

HOPKINS, Gerard Manley. Poems and prose. Organização W. H. Gardner. Harmondsworth (Inglaterra): Penguin, 1976.

PESSOA, Fernando. Poesia 1902-1917. Organização Manuela Parreira da Silva, Ana Maria Freitas e Madalena Dine. São Paulo: Companhia das Letras, 2006.

Recebido em: 12/02/2014

Aceito em: 23/05/2014 